\title{
A Study on the Rationale of Social Media Use by the Students of King Khalid University
}

\author{
Sayed Salahuddin Ahmed ${ }^{1} \&$ Abdulkhaleq Q. A. $\operatorname{Hassan}^{2}$ \\ ${ }^{1}$ King Khalid University, Saudi Arabia \\ ${ }^{2}$ King Khalid University, Saudi Arabia \\ Correspondence: Sayed Salahuddin Ahmed, Department of English, College of Arts and Science, King Khalid \\ University, P. O. Box 900, Zip Code 61913, Mohayel Assir, Kingdom of Saudi Arabia. Tel: 966-053-225-5706. \\ E-mail: salahuddin_ju@yahoo.com
}

Received: May 19, 2017 Accepted: July 2, 2017 Online Published: July 4, 2017

doi: $10.5539 /$ elt.v10n8p43 URL: http://doi.org/10.5539/elt.v10n8p43

\begin{abstract}
Is not it deplorable that in a country that tops in the entire world in using several social media sites does not utilize the same media in acquiring knowledge and skills? In Saudi Arabia, undergraduate students spend a significant amount of time on social media every day, but they are reluctant (or not motivated enough) to use the same media for educational purposes. This study was carried out on the undergraduate English majors of King Khalid University in Muhayil Asir in Saudi Arabia. In the English department, every student carries at least one smart phone with Internet connection, and they are found occupied with their phones on the campus, sometimes even in classrooms, but they are weak both in subject knowledge and skills of English language. The teachers-cum-researchers were baffled with students' competence because regular users of Internet and social media are supposed to be updated with the subject knowledge as well as confident in using English language. The researchers designed an empirical study to explore students' rationale of using the social media and their language preference. The study concludes with gloomy findings that students use the media mainly for entertainment and ineffective communication in English language. The worst fact is: they are not motivated enough to use the social media for educational purposes.
\end{abstract}

Keywords: rationale, social media, 2.0 technologies, MOOCS, technoself studies, English language skills, motivation

\section{Introduction}

\subsection{Introduce the Problem}

In Saudi Arabia, social media is getting increasingly popular day by day, mostly due to the youthfulness of the country's population. According to the Economist, Saudi Arabia has the world's highest penetration of Twitter users. Global Media Insight (GMI), the first Digital Agency in the Middle East region, claims that as of 2016 total population in Saudi Arabia was 31.85 million and of them 20. 29 million (63.7\%) was active internet users. The country has 11 million active social media accounts. GMI presented the statistics of social media use in Saudi Arabia as of 2016 in the following manner:

\begin{tabular}{lll}
\hline Social media & Number of users (in Millions) & Percentage of the total population \\
\hline WhatsApp & 8.59 & $27 \%$ \\
Face book & 7.96 & $25 \%$ \\
Twitter & 6.37 & $20 \%$ \\
Face book Messenger & 6.37 & $20 \%$ \\
Instagram & 5.41 & $17 \%$ \\
Google+ & 4.77 & $15 \%$ \\
Skype & 4.45 & $14 \%$ \\
Snapchat & 4.41 & $13 \%$ \\
LinkedIn & 3.50 & $11 \%$ \\
\hline
\end{tabular}


Increasing trend in the use of social media in Saudi Arabia has turned e-mail a cliché. "If I send my students an assignment, I have to tweet to tell them to check their inboxes!" says a university professor in the eastern city of Dhahran. Social media has won over the ways we interact with one another- first of all on a personal level, and then on a business level, with marketing experts quickly reaching target consumers through direct communication. The possibilities for social media in education are equally stirring. Universities do not even need to convince students of the value of social media - the students have already been used to them; so it makes sense to interact with them in their well-known online world. Now the question arises: how in Saudi Arabia, where the youths are exceedingly pre-occupied with social media, are not using the same media effectively for learning?

\subsection{Explore Importance of the Problem}

Every day, the youths in Saudi Arabia use social media for long hours; at the same time, they struggle to learn skills of English language. Using social media and learning English are so much connected, but the Saudi youths do not see the connection; they do not use the technique they have at their fingertips. This is important to know what drives them to use social media and which language they prefer to use on social media. When we will learn answers to these two questions, we can relate their use of social media to their learning of English language.

\subsection{Describe Relevant Scholarship}

(a) Social media

Merriam-Webster dictionary defines social media as "forms of electronic communication (as Web sites for social networking and micro blogging) through which users create online communities to share information, ideas, personal messages, and other content (as videos)". Wikipedia defines Social media as "computer-mediated tools that allow people or companies to create, share, or exchange information, career interests, ideas and pictures/videos in virtual communities and networks". The social media services currently available introduce challenges of definition; however, there are some common features of social media: (a) social media are Web 2.0 internet-based applications, (b) user-generated content (UGC) is the lifeblood of the social media organism, (c) users create service-specific profiles for the site or app that are designed and maintained by the social media organization, and (d) social media facilitate the development of online social networks by connecting a user's profile with those of other individuals and/or groups. Social media depend on mobile and web-based technologies to create highly interactive platforms through which individuals and communities share, co-create, discuss, and modify user-generated contents. They introduce substantial and pervasive changes to communication between businesses, organizations, communities, and individuals which are the focus of the emerging field of technoself studies. Social media differ from traditional or industrial media in many ways, including quality, reach, frequency, usability, immediacy, and permanence. They operate in a dialogic transmission system (many sources to many receivers). This is in contrast to traditional media that operates under a monologic transmission model (one source to many receivers). At the same time, the total time spent on social media in the U.S. across PC and mobile devices increased by 99 percent to 121 billion minutes in July 2012 compared to 66 billion minutes in July 2011. For content contributors, the benefits of participating in social media have gone beyond simply social sharing to building reputation and bringing in career opportunities and monetary income, as discussed in Tang, Gu, and Whinston (2012).

(b) Use of social media in Saudi Arabia

Although North America is the leading region in internet penetration, the Middle East is also increasingly connected, with an internet penetration above the world average - fifty three percent of the total population. Notwithstanding, this increase in access to internet services, largely supported by increasing access to mobile devices and decreasing costs of internet packages, international observers attract attention to censorship practices in various countries in the region. According to a 2015 Freedom House, Index regarding the internet freedom in selected Middle East and North African countries, Syria and Iran jointly occupied the penultimate place in internet freedom with 87 index points. With a 73 index, Saudi Arabia received a 'not free' status from the International organization. However, as internet censorship usually affects access to certain types of content, as regulated by the state, it largely does not affect communication between people. As a result, social media has become increasingly popular in Arab countries, where over 40 percent of users access social media platforms to connect with friends up to several times a day. In Middle East and Africa, the number of Facebook users is expected to reach 265.4 million by 2018 .

Saudi Arabia ranks seventh globally in terms of individual accounts on social media, with seven accounts for each individual - three of which are active - while the number of tweets on Twitter exceeds 500,000. This was revealed in a survey by Saudi Aramco, which was based on official statistics from social media websites. The 
study showed that 26 percent of Saudi teenagers use Snapchat, putting Saudi Arabia in the eighth position globally, in terms of teenagers who use the website. Saudi Arabia ranks $14^{\text {th }}$ in terms of WhatsApp users with 56 percent of mobile phone users. The workshop on the future of social media held in Alkhobar in Saudi Arabia in November, 2015. Benjamin Ampen, head of sales, Middle East and North Africa (MENA) at Twitter, and Marwan Zein of LinkedIn joined the workshop. The workshop discussed the future of social media networks in addition to information and tips about the best practices in the field of effective communication. The Twitter head of sales said the percentage of Twitter users is very large in Saudi Arabia. He pointed out that the hashtag during the opening of the King Abdullah Sports City in Jeddah was one of the most effective ones in the Middle East, in addition to the hashtag of Makkah Life. He said around 80 percent of Twitter users post tweets on their mobile phones and 90 percent watch videos on their mobile phones. One of the participants said 33 percent of Snapchat users in Saudi Arabia allocate two hours of use on daily basis, while 29 percent use it for one hour each day. He said 50 percent of Snapchat users are in Riyadh.

In 2015, Arab News, leading English daily of the gulf, ran a survey where nearly 1,796 people took part. 69 percent of the participants said that Twitter would remain popular in the Kingdom. 35 percent of the total population was active social media users. The most popular social network was WhatsApp with a 27 percent penetration rate. On an average, a Saudi followed around 609 Twitter accounts and was followed by 741 people. A Saudi sent around five tweets per day. The re-tweeting of their tweets reached 87 percent. They were mostly active on Twitter between nine in the morning till midnight. Of the total Twitter users in the Arab world, 40 percent are Saudis. They send 210 million tweets each month. There are 9 million users of Twitter in the Kingdom, which is a growth of 80 percent compared to 2013. Ammar Mohammad, a social media expert, was quoted as saying in a local publication that Twitter was popular in the Kingdom due to natural factors, including trust and swift spread of information as well as the presence of decision-makers on the platform. He said that an ordinary user searches for easy information. Saudis were among the first users of Twitter when it was launched in 2006. The users find it the most appropriate platform for self-development, communication and getting information swiftly. BBC News reported, "With 2.4 million users, Saudi Arabia is home to more than 40 per cent of all active Twitter users in the Arab region, says the Dubai School of Government. The country accounts for 10 per cent of all Facebook users in the Arab region. Saudi Arabia has the highest per capita YouTube use of any country in the world. Many Saudis turn to YouTube and other online broadcasters for light relief. A recent survey found that Saudis watch an average of seven YouTube videos a day. The youthfulness of the population helps explain the popularity of social media. The largest number of users are aged 26 to 34 .

\section{(c) Role of social media sites on education and learning}

Social media sites have strong influence on education and learning. According to usage statistics collected earlier in 2016 by Of com, 66 percent of all adults aged 16+ have a profile on at least one social networking site, and though the report does not break down these figures by age group, it is reasonable to assume that among those of university age, that percentage could potentially be much higher. Schools, colleges and universities use social media as a platform for showcasing their achievement and reputation for marketing purpose. Many faculties and societies have accustomed to the fact that 75 percent of students admit to being on Twitter 'all the time' and are using the micro-blogging site as a forum to share content, encourage debate and answer queries, with some even setting up hashtags for individual courses to create online discussion communities for their students. Indeed, the latter is a strategy believed by some educators to provoke more thoughtful responses from students- the idea being that when they know their comments will be read by the peers and not just by their lecturer, they not only consider what to say more carefully but pay more attention to how they write it and take more care with grammar, spelling and punctuation. Moreover, social media have proved their value in distance learning that allows people of different ages and professions to take college courses at convenient time, pace and place. Distance learning providers are obliged by the very nature of their courses to keep pace with any trends and technological advances which promote communication with students and enhance the learning experience. Early data from some of the most successful Massive Open Online Courses (MOOCs) indicates that student participation is greatly increased when social media platforms are integrated with the learning program, and at the same time, student drop-out rates are reduced. Though MOOCs may be a relatively new phenomenon, these early indications suggest that the introduction of social media can have a very positive influence, one which universities cannot afford to ignore. With 7 out of 10 people now owning a smartphone, and social media usage accounting for over 30 percent of online smartphone activity, this is a communication channel that teachers simply can not afford to overlook; though perhaps the greater challenge will be in selecting the frequency and volume of information they want to share in this way- too much and they risk effectively 'spamming' their audience, too little and they fail to engage them. 
Statistics show that 47.5 per cent of the Saudi population is engaged in the internet use. The percentage is an equivalent of 13.6 million users in the country ("Q1 2012," 2012). According to "Digital Media in Saudi Arabia" (n.d.), 82 per cent of these internet users utilize Face book and 80 per cent of Saudi Arabian YouTube browsers utilize social media tools. While based on "number of Twitter users in Saudi Arabia" (2012), the number of Twitter users in the country has increased to 3000 per cent in June, 2012. These figures exhibit huge effect of technology on the young generation. This is also the reason why universities in the country have started utilizing social media for teaching and learning purposes.

\subsection{State Hypothesis and Their Correspondence to Research Design}

Title of this study sparked in the minds of the researchers when they observed that their students own smart phones and use the Internet for long hours a day; but at the same time, they are weak in English language. The researchers decided to identify the possible links between their use of the Internet and their proficiency in English language. Hypothetically the teachers-cum-researchers thought if students use the Internet substantially in English language, they are supposed to practice all the four skills of English language and ultimately they would be proficient users of English language.

Research questions:

(a) What are the roles of social media on education and learning?

(b) How is social media used in Saudi Arabia?

(c) How is social media used by students of King Khalid University?

(d) Why do students of King Khalid University use social media?

(e) Which language do the students of King Khalid University prefer in using social media?

\section{Method}

\subsection{Participant (Subject) Characteristics}

Undergraduate English language majors of King Khalid University at College of Science and Arts in Muhail Asir, Saudi Arabia participated in the study.

\subsection{Sampling Procedures}

115 English language majors of the College of Arts and Science at King Khalid University in Muhayil Asir were selected randomly from different semesters. They were asked to fill in a questionnaire of 16 questions.

\section{Results}

The study revealed surprising facts. The goal of the study was to explore the reasons English majors at College of Arts and Science of King Khalid University use the social media for and the language they prefer in using the sites. After the research was completed, the researchers were baffled to know that the students participating in the study use the media for entertainment and leisure purposes only; they do not use the media for educational purposes. They are not even motivated enough to do that. It was also evident from the study that students use Arabic mostly and English rarely while using social media.

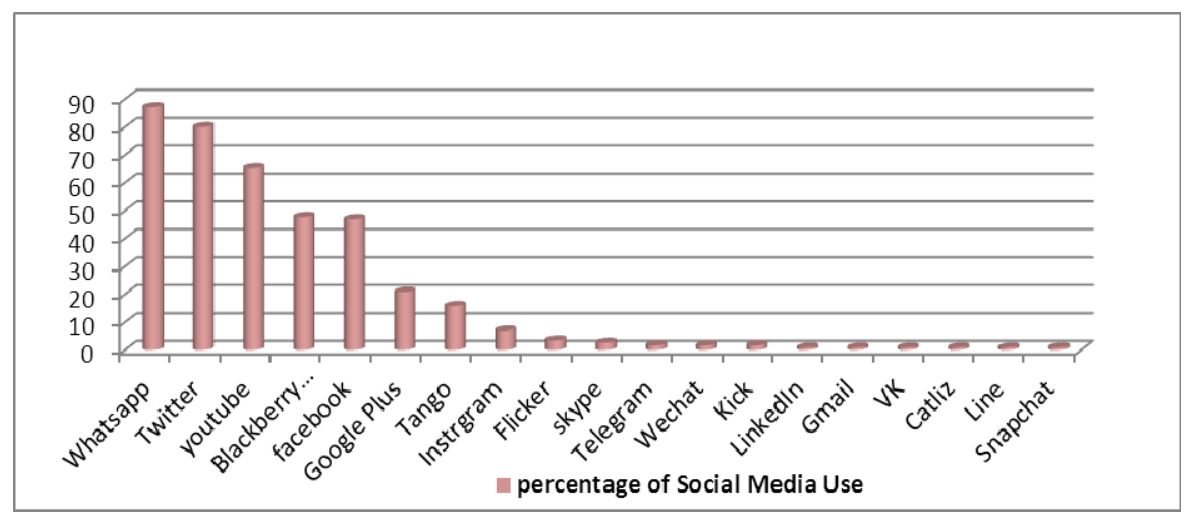




\section{Discussion}

The participants mentioned 17 sites of social media where WhatsApp tops the list with 100 users followed by Twitter with 92, YouTube with 75, blackberry messenger with 55 and Face book with 54 users. Among less used sites, Google Plus and Tango have significant number of users- 24 and 18 respectively.

The study shows that every day 20.8 per cent of the participants spends more than 5 hours on social networking sites, while 13.9 percent spends 3-4 hours, 22.6 per cent spends 2-3 hours, 18.2 percent spends 1-2 hours and 11.3 percent of the participant spends around 1 hour on the sites. On average, every student participating in the survey has got 150 friends on social media; but unfortunately, each participant has got 14 friends in average with whom they occasionally communicate in English. For them, the pick hours for using social media vary. 39.1 percent of the participants prefers using the social media during $8 \mathrm{pm}$ to $12 \mathrm{am}, 24.3$ per cent loves to appear on the sites during $12 \mathrm{am}$ to $2 \mathrm{am}, 19.1$ per cent likes the slot of $5 \mathrm{pm}$ to $8 \mathrm{pm}, 9.5$ per cent rather checks in on the sites during $11 \mathrm{am}$ to $12 \mathrm{pm}, 5.2$ per cent uses the sites during 8 am to $12 \mathrm{pm}$, and 2.6 per cent participants appears on these sites during 2 am to $6 \mathrm{am}$. There are numerous English language learning pages on various sites of social media but only 12 participants (10.4 per cent of the total participants) have claimed to be members of at least one English language learning page.

The study reveals an alarming comparative picture of the use of the two languages - English and Arabic - on social media. It shows that they speak a lot with their friends on social media but most of the time they speak in Arabic. 34 participants (29.5 per cent) claim that every week they speak for more than 6 hours in Arabic, while only 1 student claims to speak in English for more than 6 hours in a week. Moreover, 9 students speak in Arabic for 4-6 hours with their counterpart of 5 in English; 19 students speak in Arabic for 2-4 hours a week, while 16 participants speak for the same duration in English. For a shorter duration (1-2 hours a week) use of English language takes over Arabic as 53 students use English while 31 speak in Arabic. Most striking point is: 25 participants (21.7 percent) claim that they NEVER speak in English on Social media and 9 students claim that they never talk at all on social media.

On social media, users read numerous statuses, comments, notes, news, features and other stuffs. The study asked the participants how many sentences on average they read on social media every day. The results show that 61 participants (53 per cent) read more than 20 Arabic sentences on social media every day, while only 27 students (23.4 per cent) read the same number of English sentences during the same period of time. On the other hand, 26 students read 16-19 English sentences per day with their counterpart of 13 in Arabic, while 21 participants read 10-15 English sentences and 13 students read the same number of Arabic sentences. Moreover, 35 participants go through 5-9 English sentences every day on social media, while 26 students read same number of Arabic sentences. Finally, we see that 8 students have got a very low rate (0-4 sentences a day) of reading- 6 of them read in English while only 2 read in Arabic.

Social media provide a lot of opportunities for writing. The users can chat, post status and write comments in both Arabic and English. In Saudi Arabia, the social media users usually use Arabic and rarely English. As we have observed that our students frequently write on these sites but their level of English writing is poor, so we asked them how frequently they write in English and Arabic languages because we know that regular use of English language on social media would certainly develop their writing skill. The survey has exposed that 7 students write only 0-4 sentences a day in Arabic and 9.5 per cent of the participants writes the same number of English sentences per day, while 24.3 per cent of them pen in 5-9 sentences in Arabic with their counterpart of 40 per cent in English. About writing 10-14 sentences, we find 14.7 percent participants for Arabic and 21.7 percent in English. While 16.5 percent of the participants write 15-19 sentences per day in Arabic, 20.8 per cent of them write the same number of sentences in English. Moreover, 19 students (16.5 per cent) write 15-19 in Arabic and day and 24 (20.8 percent) of them write the same number of sentences in English. Finally, 38.2 percent of students produce 20 and more sentences a day in Arabic, while 9 per cent of them write the same number in English.

Video clips are abundant on social media through different applications including YouTube. Sometimes users, site administrators and companies upload and share video clips. The clips pop up on the users' eyes in different languages when they appear online. We asked our students how frequently they watch Arabic and English video clips and they have come up with the following data: 19 participants said they never watch videos in Arabic language on social media, while 40 students said they watch 1-3 videos per day and 21 students informed that they watch 4-6 video a day. Moreover, 14 students opined that they watch 7-9 video, while 21 participants said they watch more than 9 videos in Arabic language. Interestingly enough, the statistics of the participants for watching video clips in English language is similar. 20 participants confirmed they never watch videos in 
English language, 39 students watch 1-3 such videos, 22 students opined that they watch 4-6 videos, 13 of them said they watch 7-9 videos while 21 students shared with us that watch more than 9 videos in English per day.

Watching English movies has direct impact on learning English language. So we asked our students how frequently they watch movies. We also asked their language preference. About watching movies in Arabic language or with Arabic subtitle, 11 students replied that they never watch such movies, 30 participants opined that they watch 1-3 movies every day, 39 students said they watch 4-6 of such movies, 19 of them informed us they watch 7-9 movies while 16 students said they watch more than 9 movies in Arabic language every day. On the other hand, 13 students said they never watch English movies, 32 students opined that they watch 1-3 movies, 28 participants said they watch 4-6 movies, 21 students said they 7-9 movies and 21 participants said they watch more than 9 English movies a day.

\section{References}

http://canadianmarketer.ca

http://www.arabnews.com/news/how-many-tweets-does-saudi-send-day

http://www.bbc.com/news/world-middle-east-14703480

http://www.bbcactive.com/BBCActiveIdeasandResources/Howsocialmediaischangingeducation.aspx

http://www.globalmediainsight.com/blog/saudi-arabia-social-media-statistics/

http://www.igi-global.com/article/state-social-media-saudi-arabia/76361

http://www.statista.com/statistics/284451/saudi-arabia-social-network-penetration/

http://www.topuniversities.com/publications/students-online-usage-global-trends-report-2013

https://en.wikipedia.org/wiki/Social_media

https://smbp.uwaterloo.ca/2016/03/can-social-media-give-online-education-a-brighter-future/

https://www.hrw.org/sites/default/files/reports/midintnt996.PDF

https://www.statista.com/statistics/244926/number-of-facebook-users-in-the-middle-east-and-africa

Tang, Q., Gu, B., \& Whinston, A. B. (2012). Content Contribution for Revenue Sharing and Reputation in Social Media: A Dynamic Structural Model. Journal of Management Information Systems, 29, 41-75. https://doi.org/10.2753/MIS0742-1222290203

\section{Appendix: The questionnaire}

Use of social networking sites by the students of King Khalid University in Saudi Arabia

\section{Student's}

name:

Department: .Level:

College:

City/village of origin:

Age:. Marital status:

Father's occupation:

(As an ethical policy, students' personal information will be kept secret and pseudonyms will be used in the thesis, if necessary).

1. Check the social networking sites you use regularly. (you can check as many as you use)
(a) Facebook
(b) Twitter
(c) Skype
(d) My Space
(e) What'sapp
(e) LinkedIn
(f) Flickr
(g) Google Plus
(h) Pinterest
(i) $\mathrm{VK}$
(i) YouTube 
2. Everyday you use social networking sites for
(a) $1 \mathrm{hr}$
(b) $1-2 \mathrm{hrs}$
(b) 2-3 hrs
(d) $3-4$ hrs
(d) $4-5 \mathrm{hrs}$
(e) More than $5 \mathrm{hrs}$

3. Total number of friends you have on these social networking sites

4. Number of friends with whom you need to chat (speaking or writing) in English?

5. You use these sites most during the period
(a) $8 \mathrm{am}-12 \mathrm{pm}$
(b) $12 \mathrm{pm}-5 \mathrm{pm}$
(b) $5 \mathrm{pm}-8 \mathrm{pm}$
(c) $8 \mathrm{pm}-12 \mathrm{am}$
(c) $12 \mathrm{am}-2 \mathrm{am}$
(d) $2 \mathrm{am}-6 \mathrm{am}$

6. Are you a member of any English learning page?
(a) Yes
(b) No

If yes, Please write down names of those pages and sites

7. Every week, you speak in Arabic on social networking sites (e.g. skype, google+ video chat, facebook video chat, etc.)
(a) $\mathrm{O} \mathrm{hr}($ b) 1-2 hrs
(c) 2-4 hrs(d) 4-6 hrs
(e) more than $6 \mathrm{hrs}$

8. Every week, on average, you speak in English on social networking sites (e.g. skype, google + video chat, facebook video chat, etc.)
(a) $\mathrm{O} \mathrm{hr}$ (b) 1-2 hrs
(c) 2-4 hrs(d)4-6 hrs (e) more than $6 \mathrm{hrs}$

9. Every day, you read Arabic sentences on social networking sites
(a) 0
(b) $5-10$
(c) $10-15$
(d) $15-20$
(e) more than 20

10. Every day, you read English sentences on social networking sites
(a) 0
(b) $5-10$
(c) $10-15$
(d) 15-20 (e) more than 20

11. Every day you write Arabic sentences on social networking sites (in the form of chatting, writing comments, putting status, etc.)
(a) 0
(b) $5-10$
(c) $10-15(d) 15-20$ (e) more than 20

12. Every day you write English sentences on social networking sites (in the form of chatting, writing comments, putting status, etc.)
(b) 0
(b) 5-10
(c) $10-15$ (d) $15-20$
(e) more than 20

13. Every day, you watch video clips in Arabic
(a) 0
(b) 1-3
(c) 4-6
(d) $7-9$
(e) more than 9

14. Every day, you watch video clips in English
(a) 0
(b) 1-3
(c) 4-6
(d) 7-9
(e) more than 9

15. Every week you watch movies in Arabic (or with Arabic subtitle)
(a) 0
(b) 1-3
(c) 4-6
(d) 7-9
(e) more than 9 
16. Every week you watch English movies
(a) 0
(b) 1-3
(c) 4-6
(d) 7-9
(e) more than 9

17. Every week you watch English movies

(b) 0

13

(c) 1-3

32

(d) 4-6

28

(e) 7-9

21

(f) more than $9 \quad 21$

\section{Copyrights}

Copyright for this article is retained by the author(s), with first publication rights granted to the journal.

This is an open-access article distributed under the terms and conditions of the Creative Commons Attribution license (http://creativecommons.org/licenses/by/4.0/). 